\title{
Strengthening the Cultivation of College Students' Compressive Psychological Diathesis
}

\author{
Leilei Ji
}

Linyi University 276000

Keywords: colleges and universities; college students; anti-stress psychology; become success

\begin{abstract}
At present, college students in our country generally have poor anti-compression ability, which is mainly manifested in the fragile situation in the face of setbacks and difficulties, and it is easy to be depressed. As college teachers, we must analyze the current college students' psychological pressure factors, and conduct effective communication and guidance, so as to improve college students' ability to relieve stress and control bad emotions. Based on this, this article first analyzes the factors that affect the psychological pressure of college students, and then proposes ways to enhance the college students' psychological resilience. Ultimately, through this analysis, we can improve the college students' psychological quality and promote the growth of talents.
\end{abstract}

\section{Introduction}

At present, there have been many incidents of extreme violence among university students in many colleges and universities, which have aroused widespread concern in the society, allowing people to reflect on the current situation of college students and analyze their psychological education. Therefore, colleges and universities should actively carry out education of college students' psychological health, eliminate adverse events on campus, promote social stability and campus safety, and create a good social atmosphere for college students. In specific teaching activities, it is necessary to increase the training of students' ability to resist stress, improve their mental bearing capacity, guide students toward a healthy psychological state, reduce the occurrence of adverse events on campus, and give full play to the ideological and political functions of colleges and universities.

\section{Factors Affecting College Students' Psychological Stress}

\subsection{Social Class Contradiction Triggers College Students' Negative Emotions}

The social and psychological problems are caused by long-term accumulation. There are many contradictions in our society, and people do not agree with the social phenomena. First, the social class is becoming more and more obvious. The gap between the rich and the poor is growing. Many people are unbalanced in their mentality, especially the laboring people live at the foot of the social ladder. At present, the process of urbanization is getting faster, and the pressure on people to survive is increasing. This phenomenon has also had a great impact on college students. Second, people in today' s society are weak, lack of integrity, and people are pursuing more utilitarianism. Due to the social and economic development, there is a lack of communication between people, making people lack of mutual communication and warmth. Finally, social injustice has exacerbated the pressure of the underlying people's lives. The lack of social welfare guarantees has resulted in the lack of care for the disadvantaged groups. These social statuses have caused great confusion for contemporary college students and increased psychological burden and pressure.

\subsection{Factors Directly Related to the Interests of Students}

After entering the colleges and universities, students will experience a relatively large change in their living environment. The cost of living will also increase. This will cause many families to 
face a relatively serious financial burden college student because of the rising cost of living . Excessive stress leads to a greater influence on their own emotions and psychology . Compared with students with better surrounding economic conditions, they will also have a certain level of inferiority. This will also be an important factor leading to students ' negative and depressive mentality . [1] In addition, the dual pressures in learning and employment are also important factors that cause students to experience psychological burdens and bad emotions . College students need to learn a lot of professional knowledge, and also need to conduct a large number of certificate examinations, which leads to the pressure on students ' learning . Excessively large , there is also a lot of pressure on the employment situation in the future. These students often experience depressing situations in the daily learning process, but they also lack expectations for the future . This is also the cause of stress and malady among college students and bad emotion [2] .

\section{Some Ways to Strengthen Students' Compressive Psychological Quality with the help of College Ideological and Political Education}

In the course of ideological and political education in colleges and universities, it is also necessary to strengthen the students ' anti-stress psychological quality as an important teaching content, so that in the process of carrying out ideological and political education, students ' anti-stress psychological quality can be effectively improved in order to get good teaching results. However, colleges and universities in our country are still trying to cultivate and educate students on their anti-stress psychological quality. There are also many problems of the specific application process, which requires the relevant teaching staff to be able to carry out the education training model . Constantly optimize and improve, to enhance the education effect of ideological education throughout the university .

\subsection{Guide Students to Recognize Setbacks Correctly}

Only by guiding college students to face up to setbacks, we must also make reasonable choices of resolving measures in order to effectively avoid the impact on setbacks on students and further improve the overall quality of students. Therefore, in the process of ideological and political education in colleges and universities, it is necessary to guide students to recognize the commonness and universality of setbacks so that students can no longer be afraid of setbacks and can use their frustrations to gain their own training. In the setbacks, the overall quality and psychological quality of the team have been significantly improved, and thus a good setback has been achieved. For those patients that due to large setbacks are psychologically impacted in part, the counselor can teach students to effectively vent their anxieties, depression, and other undesirable emotions through the transfer method and the catharsis method. This can also provide good way to resolve the frustration [3] .

\subsection{Strengthen the Training of Students' Anti-stress Psychological Quality}

In the course of ideological and political education in colleges and universities, it is necessary to further to strengthen the education of the students ' mental health so that the students ' ability to resist pressure can be effectively improved, in order to obtain a good training effect of psychological resistance to stress . In the specific ideological and political course teaching process , the counselor can provide students with a knowledge of mental health by strengthening the psychological training propaganda, conducting stress-resistant psychological lectures, and giving college students regular psychological counseling. Under this mode of education, students can also have an accurate assessment of their own resistance to stress, can take appropriate measures to solve the problem of the face of psychological problems, so as to obtain a good effect of psychological training [4]. In addition, in some anti-stress psychological quality training work, the instructors are required to continuously strengthen the interaction between the teachers and students, and through continuous communication, they can also find out the intrinsic roots of undergraduate pressure in time and be able to target the students of the current stage . Faced with the setbacks and problems to help solve. Finally, the counselor should actively encourage and guide college students to carry out social practice activities. This can also guide students in the 
specific practice process to continue to temper and enhance their own psychological quality, so as to make their own anti-stress psychological quality can get a significant boost .

\subsection{Teacher's Reasonable Construction to Help College Students Resist Frustration Measures}

When individuals suffer setbacks, a balance of emotional balance and a stable defensive mechanism will form deep into their hearts. However, due to the lack of their social experience and poor psychological quality, some students have also caused setbacks, it can't construct the frustration measures in time, and it will lead to a greater impact on their lives and learning . Therefore, the teaching staff of ideological and political education courses also need to have a clear grasp of the psychological status of college students, and be able to take rational and defensive behavior in a timely manner to help college students to effectively prevent various frustrations . For example, when students encounter setbacks that are too high to achieve, the counselor can guide students to appropriately reduce their goals, so that they can effectively improve students ' learning and life enthusiasm, thus achieved good setbacks and get good resistance effect [5] . In addition , when the students encounter difficulties that they cannot solve, the counselor can also guide students to conduct a comprehensive analysis of the incident based on their own life experience and give some guidance. This can also promote students. Their self-adjustment ability has been significantly improved, and they have also played a good defense against the setbacks encountered in life and learning .

\section{Conclusion}

In the course of ideological and political education in colleges and universities, it is also necessary to strengthen the training of students ' anti-stress psychological diathesis, and it is necessary to regard the improvement in students ' anti-stress psychological diathesis and the cultivation of comprehensive diathesis as a teaching focus. Only in this way can students be enabled to the frustration's ability to resist pressure which has been effectively improved and good teaching results that have been achieved. This article briefly discusses some of the influencing factors that affect the psychological pressure in college students at this stage, and proposes several solutions to the problems . It hopes to provide some theoretical theories and help for the cultivation of college students ' anti-stress psychological quality of China .

\section{References}

[1]. Yang Min. On the college students' behavior under the current ideological and political education in colleges and universities[J]. Education and Occupation. 2012(33)

[2]. Zhang Qian, Tang Jihong. Research on the status quo and countermeasures of college students' anti-frustration psychological quality training [J]. Education and Occupation. 2012 (33)

[3]. Shen Yanfei, Li Yinxiang. Psychology Foundation of Guiding Mechanism in Ideological and Political Theory Course [J]. Theoretical Front in Colleges and Universities. 2012 (11)

[4]. SU Ran. Strategies for integrating mental health education into ideological and political education among college students [J]. Journal of Changchun Institute of Education.2012 (10)

[5]. Xu Yongjin, Zhang Minggang. The construction of college students' comprehensive quality training system[J]. Research in Ideological and Political Education.2011(04) 